Article

\title{
Cross-Linking Modification of Ammonium Polyphosphate via Ionic Exchange and Self-Assembly for Enhancing the Fire Safety Properties of Polypropylene
}

\author{
Yingtong Pan $\mathbb{1}$, Zhonglin Luo and Biaobing Wang * \\ Jiangsu Key Laboratory of Environmentally Friendly Polymeric Materials, School of Materials Science and \\ Engineering, Jiangsu Collaborative Innovation Center of Photovoltaic Science and Engineering, Changzhou \\ University, Changzhou 213164, China; pyt15261177360@126.com (Y.P.); zhonglinluo@cczu.edu.cn (Z.L.) \\ * Correspondence: biaobing@cczu.edu.cn; Tel./Fax: +86-0519-8633-0075
}

Received: 27 October 2020; Accepted: 20 November 2020; Published: 23 November 2020

\begin{abstract}
Modified ammonium polyphosphate (MAPP) was prepared as a novel mono-component intumescent flame retardant (IFR) via the ionic exchange between ammonium polyphosphate (APP) and piperazine sulfonate, which is synthesized by self-assembly using 1-(2-aminoethyl) piperazine (AEP) and $p$-aminobenzene sulfonic acid (ASC) as raw materials. This all-in-one IFR integrating three functional elements (carbon, acid, and gas source) showed more efficient flame retardancy and excellent smoke suppression as well as better mechanical properties than the conventional APP. The incorporation of $22.5 \mathrm{wt}$ \% MAPP into polypropylene (PP) eliminated the melt dripping phenomenon and passed the UL-94 V-0 rating. The results of the cone calorimetry test (CCT) revealed that the release of heat, smoke, and $\mathrm{CO}$ is significantly decreased, demonstrating that this novel IFR endows PP with excellent fire safety more effectively. For PP/MAPP composites, a possible IFR mechanism was proposed based on the analysis of the pyrolysis gas and char residues.
\end{abstract}

Keywords: ionic exchange; self-assembly; modified ammonium polyphosphate; polypropylene; combustion behavior

\section{Introduction}

With the wide application of polymers in construction, electronics, and other fields, the possibility of polymeric materials being exposed to flames has increased significantly [1]. Most polymeric materials are liable to combust, possessing the characteristics of a high heat release rate [2], therefore, improving the fire resistance of polymeric materials is of great significance for diminishing fire hazards and protecting the safety of people's lives.

Polypropylene, one of the commercially available general-purpose plastics, has been applied in agriculture, industry automobile manufacturing and film packaging, owing to its low toxicity, excellent mechanical properties, electrical insulation, and chemical resistance [3,4]. However, its further application and development are restricted by its disadvantages, including the inherent flammability, severe dripping behavior, and the release of smoke and toxic gases during combustion [5]. Therefore, it is particularly significant to improve both its flame retardancy and smoke suppression performance simultaneously. Recently, phosphorus-based (9,10-dihydro-9-oxa-10-phosphaphenanthrene-10-oxide, APP), nitrogen-based (melamine phosphate, melamine salt of pentaerythritol phosphate kaolinite), mineral-based (aluminum trihydroxide), and carbon-based (graphene) flame retardants have gradually replaced the halogen-containing flame retardants due to their high efficiency, low smoke, and low toxicity $[6,7]$. Among them, the intumescent flame retardant (IFR), which is made of an acid source (APP, 
organic phosphoric acid and phosphate ester), blowing agent (urea, melamine, dicyandiamide and their derivatives) and a carbonizing agent (pentaerythritol and piperazine derivatives) is popular. Tang et al. [8] synthesized two charring agents (named as PT-cluster and PT) with different piperazine/triazine group aggregation structures, which generated excellent intumescent flame retardant effects with APP in PP composites. Although APP can act as both an acid source and a blowing agent, it still fails to achieve a good IFR effect in the case of the usage of APP alone [9]. Many strategies have been developed to improve its flame retardancy. The most important choice is to microencapsulate APP with silane coupling agents [10], polyurethane (PU) [11], melamine-containing polyphosphazene (PZMA) [12], or melamine-formaldehyde (MFT) [13] via in situ polymerization. The microencapsulation modification of APP has improved the flame retardant efficiency of PP more or less, but it is still needs to be compounded with a charring agent for which the preparation procedures are complicated and time-consuming. Therefore, the preparation of a mono-component flame retardant which integrates all three sources of IFR has become a research hotspot. Shao et al. tried to modify APP with various organic amines, such as ethylenediamine (EDA) [14], ethanolamine (ETA) [15], diethylenetriamine (DETA) [16], and piperazine (PA) [17] via ionic exchange to prepare three-in-one flame retardant. This method was facile but the flame retardancy still needed to be improved. Thus, a novel modification technology should be developed to overcome this problem.

Self-assembly technology has been applied to produce substances with specific structures by exploiting the interactions between structural units, such as hydrogen bonding and ionic interactions $[4,18-20]$. Recently, self-assembly technology has been adopted to prepare flame retardants due to its facile preparation method and environmentally friendly. Su et al. [21]. modified APP with melamine-formaldehyde and phytic acid (MF-PA) as building blocks by self-assembly reaction. The results demonstrated that the dispersivity of the modified APP in the matrix has been dramatically improved, and the LOI value of the IFR-PP system reached 35\% and the UL-94 V-0 rating was achieved at a loading level of $25 \mathrm{wt} . \%$ of modified APP/CFA (4:1, weight ratio). Jin et al. [22]. prepared a novel macromolecular IFR (AM-APP) via supramolecular reactions between melamine and $p$-aminobenzene sulfonic acid, followed by an ionic exchange with APP. With the incorporation of $22 \mathrm{wt} . \%$ AM-APP and $3 \mathrm{wt} . \% \mathrm{TiO}_{2}$, polyamide 11 composites showed high LOI value, upgraded UL-94 rating, and an $81.2 \%$ reduction on $\mathrm{pHRR}$ value. Although some progress had been achieved in the modification of APP via self-assembly, it still needs to be matched with charring agents or metal oxides to pass the UL-94 V-0 rating. In addition, few pieces of literature have been reported on the synthesis of mono-component flame retardant through self-assembly technology and ionic exchange.

The current work reported the synthesis and characterization of a mono-component flame retardant prepared by self-assembly reactions between 1-(2-aminoethyl) piperazine and $p$-amino benzenesulfonic acid, followed by an ionic exchange with APP. The facile preparation method was considered environmentally friendly, using anhydrous ethanol and deionized water as the solvent. The flame retardancy, combustion behaviors, and flame retardant mechanism of the IFR-PP system were investigated in detail.

\section{Materials and Methods}

\subsection{Materials}

PP, F401, melt flow rate $=2.5 \mathrm{~g}(10 \mathrm{~min})^{-1}\left(230^{\circ} \mathrm{C}, 2.16 \mathrm{~kg}\right)$ was provided by Yangzi Petroleum Chemical Company (Nanjing, China). Ammonium polyphosphate (TY-432, crystalline form II, degree of polymerization > 1000) was purchased from Yunnan Tianyao Chemical Co., Ltd. (Kunming, China). p-Aminobenzene sulfonic acid (AR, 99.5\%) and 1-(2-aminoethyl) piperazine were supplied by Aladdin Industrial Corporation (Shanghai, China). Absolute ethyl ethanol (AR, 99.5\%) was obtained from Sinopharm Group Co., Ltd. (Shanghai, China). Deionized water was self-made. All of the commercial materials were used directly without further purification. 


\subsection{Modification of APP}

Figure 1 illustrated the modification process of ammonium polyphosphate involving two stages.

Firstly, the piperazine sulfonate (intermediate) was prepared via self-assembly as shown in stage I. Under stirring, ASC $(17.3 \mathrm{~g}, 0.1 \mathrm{~mol})$ was dissolved in deionized water at $90^{\circ} \mathrm{C}$. Hereafter, AEP $(13.1 \mathrm{~mL}$, $0.1 \mathrm{~mol}$ ) was dropped into the ASC solution at a constant titration rate $(2 \mathrm{~s} /$ drop). The reaction system was kept $95^{\circ} \mathrm{C}$ for $3 \mathrm{~h}$. After vacuum distillation and suction filtration, the straw yellow powder (AEP-ASC) was obtained and then dried at $80^{\circ} \mathrm{C}$ in the vacuum oven for $24 \mathrm{~h}$.

Secondly, the modified APP (MAPP) was synthesized via the ionic exchange between intermediate and APP as shown in stage II. To a three-neck round-bottom flask equipped with a stirrer, a thermometer and a reflux condenser were added APP $(10 \mathrm{~g}), 50 \mathrm{~mL}$ ethanol, and $20 \mathrm{~mL}$ water. The mixture was refluxed under stirring for $12 \mathrm{~h}$. Afterward, the intermediate $(10 \mathrm{~g})$ was introduced into the mixture, and the reaction continued for $2 \mathrm{~h}$. Then, the light yellow and viscous solid was obtained from vacuum filtration and washed by deionized water (removing unreacted intermediate) three times. After drying under a high vacuum at $80^{\circ} \mathrm{C}$ overnight, the final product (light yellow powder) was obtained and defined as modified APP (MAPP).

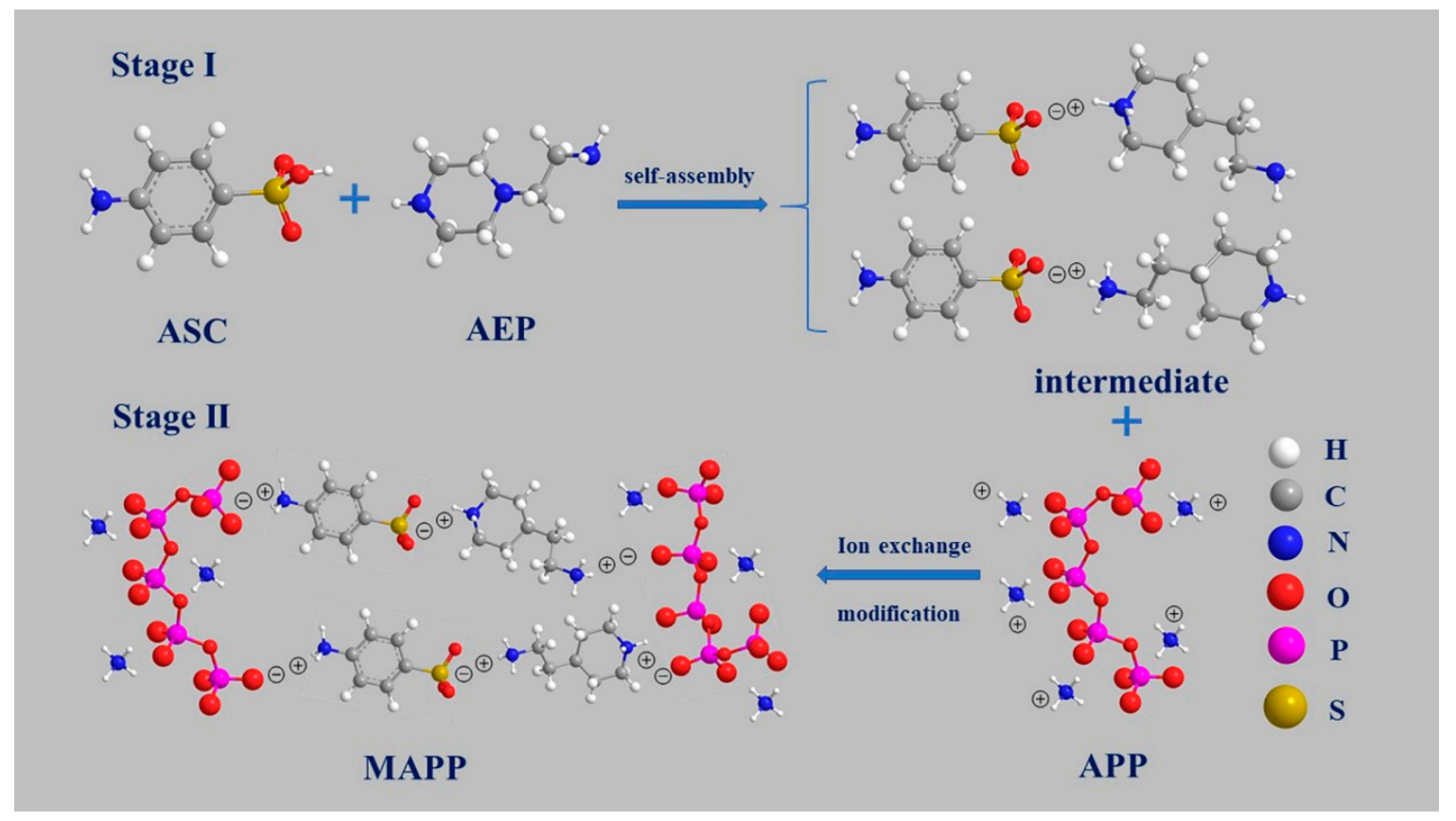

Figure 1. The synthetic route of MAPP.

\subsection{Sample Preparation}

The IFR/PP blends were obtained by mixing the APP or MAPP with different mass ratios. The specific formulas were shown in Table 1. Then the IFR/PP blends were mixed at $190{ }^{\circ} \mathrm{C}$ for 5 min in an internal mixer (US-70C, Changzhou Suyan Technology Co., Ltd., Changzhou, China). The samples for fire behavior characterization were pressed to the sheet at $195{ }^{\circ} \mathrm{C}$ for 5 min under $10 \mathrm{MPa}$ of the pressure under a plate vulcanizer (ZHY-W, Chengde Testing Machine Factory, Hebei, China). The samples for mechanical measurements were injection-molded in a miniature injection molding instrument (WZS-10D, Xinshuo Precision Machinery Co., Ltd., Shanghai, China). The melting temperature was $200^{\circ} \mathrm{C}$, the mold temperature was $40^{\circ} \mathrm{C}$, the holding pressure was $0.6 \mathrm{MPa}$, and the holding time was $10 \mathrm{~s}$. 
Table 1. Detailed results for PP and its flame-retardant blends from UL-94 and LOI tests.

\begin{tabular}{ccccccc}
\hline Sample ID & $\begin{array}{c}\text { PP } \\
\text { wt. } \%\end{array}$ & $\begin{array}{c}\text { APP } \\
\text { wt. } \%\end{array}$ & $\begin{array}{c}\text { MAPP } \\
\text { wt. } \%\end{array}$ & $\begin{array}{c}\text { Dripping } \\
\text { or Not }\end{array}$ & $\begin{array}{c}\text { UL-94 Rating } \\
\mathbf{3 . 2} \mathbf{~ m m}\end{array}$ & $\begin{array}{c}\text { LOI } \\
\mathbf{\%}\end{array}$ \\
\hline Pure PP & 100 & 0 & 0 & Yes & No rate & 17 \\
PP/20\%APP & 80 & 20 & 0 & Yes & No rate & 17 \\
PP/22.5\%APP & 77.5 & 22.5 & 0 & Yes & No rate & 18 \\
PP/25\%APP & 75 & 25 & 0 & Yes & V-2 & 19 \\
PP/20\%MAPP & 80 & 0 & 20 & Yes & V-2 & 22 \\
PP/22.5\%MAPP & 77.5 & 0 & 22.5 & No & V-0 & 30 \\
PP/25\%MAPP & 75 & 0 & 25 & No & V-0 & 32 \\
\hline
\end{tabular}

\subsection{Characterization}

The Fourier transform infrared (FTIR) spectra were scanned by a Perkin Elmer instrument (Waltham, MA, USA) at room temperature. The samples were mixed with $\mathrm{KBr}$ pellets including $0.5 \mathrm{mg}$ sample and $50 \mathrm{mg} \mathrm{KBr}$ and scanned 32 times over a spectral range of $4000-450 \mathrm{~cm}^{-1}$ with a resolution of $4 \mathrm{~cm}^{-1}$.

X-ray diffraction (XRD) test was carried out by a power D/MAX2500 diffraction (Rigaku Corporation, Tokyo, Japan) using Cu Ka radiation under a scanning rate of $3^{\circ} / \mathrm{s}$ from $5^{\circ}$ to $60^{\circ}(2 \theta)$.

X-ray photoelectron spectroscopy (XPS) was determined by an ESCALAB 250XI system (Thermo Fisher, Waltham, MA, USA).

The microstructures of flame retardants, char residues, and sections were measured using an SEM instrument (Zeiss SUPRA55, Jena, Germany). The specimens were sputter-coated with a conductive gold layer before observation.

The UL-94 flammability classification was measured by a CZF-5 instrument (Shine Ray Instrument Co. Ltd., Nanjing, China) according to ASTM D3801. The dimensions of the samples are $130 \mathrm{~mm} \times$ $13 \mathrm{~mm} \times 3.2 \mathrm{~mm}$.

Limiting oxygen index (LOI) was measured by an LOI analyzer (JF-3, Jiang Ning Co. Ltd., Nanjing, China). The dimensions of the samples are $130 \mathrm{~mm} \times 6.5 \mathrm{~mm} \times 3.2 \mathrm{~mm}$ according to GB/T 2406-93 standard.

Thermogravimetric analysis (TGA) was tested by a Perkin-Elmer TGA 4000 with a heating rate of $10^{\circ} \mathrm{C} / \mathrm{min}$ under nitrogen and oxygen atmosphere at temperatures ranging from $30^{\circ} \mathrm{C}$ to $850{ }^{\circ} \mathrm{C}$. TG-FTIR analysis was carried out under a nitrogen atmosphere at a heating rate of $10^{\circ} \mathrm{C} / \mathrm{min}$ from $30^{\circ} \mathrm{C}$ to $850{ }^{\circ} \mathrm{C}$. The flame retardant samples used in the tests were all fine solid powders with a mass of $8 \pm 0.5 \mathrm{mg}$; the samples of pure PP and its blends used were block solids with a mass of $8 \pm 0.5 \mathrm{mg}$.

The flammability of pure PP and PP blends were tested by a cone calorimeter device (Fire Testing Technology, East Grinstead, UK) according to ISO 5660-1. The dimension of the square sample was $100 \mathrm{~mm} \times 100 \mathrm{~mm} \times 3 \mathrm{~mm}$, and the irradiation power was $35 \mathrm{~kW} / \mathrm{m}^{2}$.

Raman spectroscopy measurement was carried out with a DXR laser Raman spectrometer (Thermo Scientific,) using a $532 \mathrm{~nm}$ helium-neon laser line at room temperature.

Tensile measurements were conducted on a universal tensile testing machine (WDT-5, Shenzhen Kai Qiang Experimental Instrument Co. Ltd., Guangzhou, China) according to GB/T 1040-2006 at a tensile speed of $50 \mathrm{~mm} / \mathrm{min}$. The Izod notched impact strength of the specimens was measured with an impact tester (XJU-22, Chengde Testing Machine Co. Ltd., Sichuan, China) according to GB/T 1843-2008. The values of all the mechanical properties were calculated as averages over five specimens. 


\section{Results and Discussion}

\subsection{Characterization of MAPP}

\subsubsection{FTIR Analysis}

Figure 2a illustrates the FTIR spectra of AEP, ASC, and AEP-ASC. The characteristic peaks at 2939 and $2813 \mathrm{~cm}^{-1}$ are attributed to the symmetrical and antisymmetric $-\mathrm{CH}_{2}-$ stretching vibration of AEP, and the peaks at 1315 and $1120 \mathrm{~cm}^{-1}$ represent the $-\mathrm{S}=\mathrm{O}$ stretching vibration of ASC [23]. Noticeably, the peak at $2647 \mathrm{~cm}^{-1}(\mathrm{~S}-\mathrm{OH})$ [24] in the spectrum of ASC disappears and two new peaks at 2446 and $3265 \mathrm{~cm}^{-1}\left(\mathrm{NH}_{2}{ }^{+}\right.$and $\mathrm{NH}_{3}{ }^{+}$bending vibration) are observed in the spectra of AEP-ASC, which indicates the formation of $-\mathrm{NH}_{2}{ }^{+}-\mathrm{O}-$ and $-\mathrm{NH}_{3}{ }^{+}-\mathrm{O}-[1,25]$. Furthermore, the spectrum of AEP-ASC shows sharp peaks at 3469,3347 and $3232 \mathrm{~cm}^{-1}$ owing to amino groups [11]. These results demonstrate that intermediate (AEP-ASC) is obtained by self-assembly. The chemical structures of the APP and MAPP are also explored by FTIR spectra (Figure 2b). Both APP and MAPP display the typical peaks at $1263 \mathrm{~cm}^{-1}(\mathrm{P}=\mathrm{O}), 1087 \mathrm{~cm}^{-1}\left(\mathrm{P}-\mathrm{O}\right.$ symmetric stretching), and $882 \mathrm{~cm}^{-1}(\mathrm{P}-\mathrm{O}$ asymmetric vibration) [26]. As compared with the spectra of APP, however, that of the MAPP displays some new peaks which are ascribed to the absorption of the benzene ring (1600 and $689 \mathrm{~cm}^{-1}$, etc.), the stretching vibration of $\mathrm{O}=\mathrm{S}=\mathrm{O}\left(1320\right.$ and $\left.1180 \mathrm{~cm}^{-1}\right)$ and especially the $\mathrm{NH}_{2}{ }^{+}$and $\mathrm{NH}_{3}{ }^{+}$bending vibration (2481 and $3248 \mathrm{~cm}^{-1}$ ). The results initially demonstrate that the APP was successfully cross-link modified with AEP-ASC by ionic exchange.
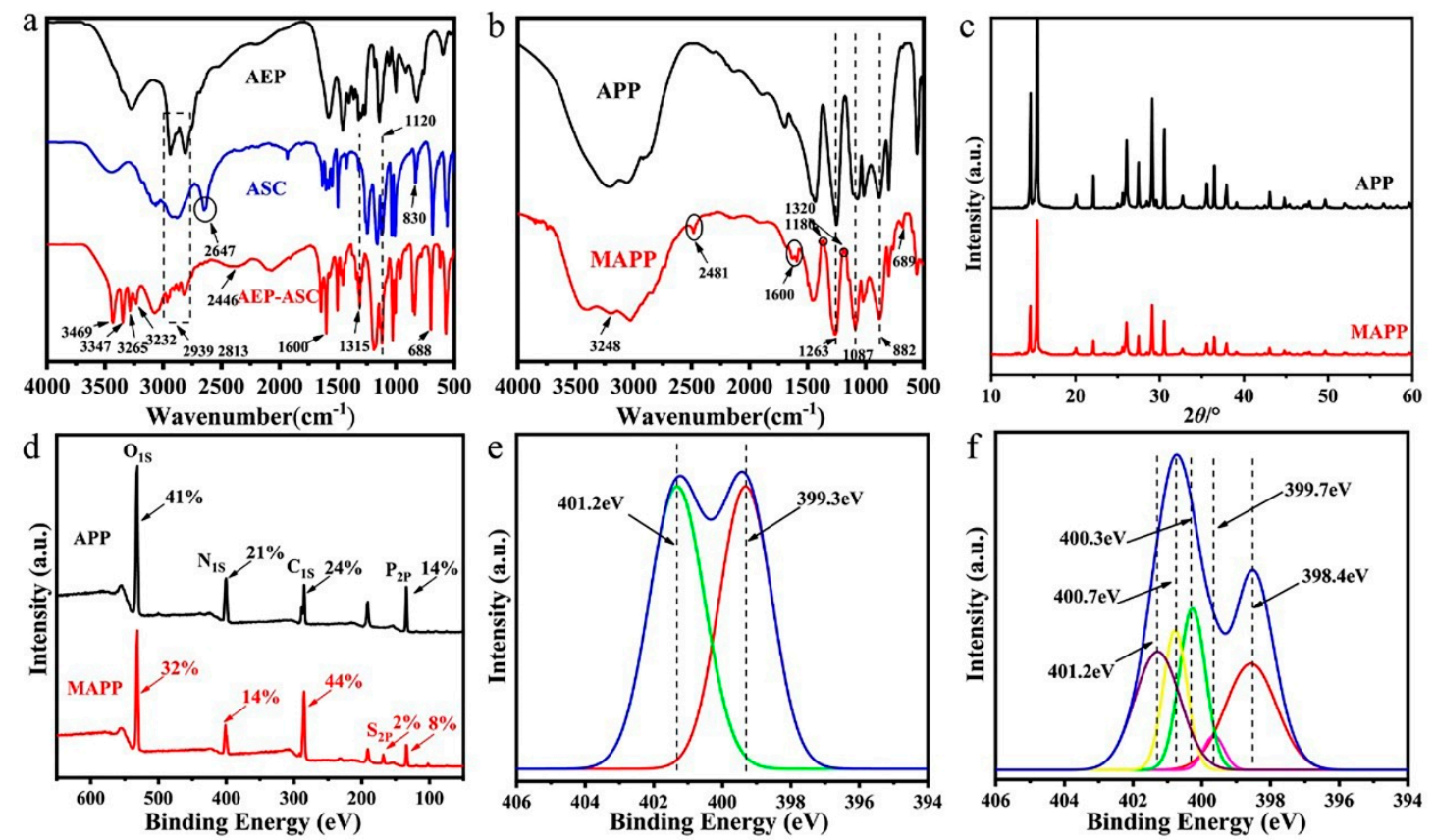

Figure 2. (a) FTIR spectra of AEP, ASC and intermediate (AEP-ASC); (b) FTIR spectra of APP and MAPP; (c) XRD patterns of APP and MAPP; (d) XPS survey spectra; $\mathrm{N}_{1}$ s XPS spectra of (e) APP and (f) MAPP.

\subsubsection{XRD Analysis}

XRD patterns of APP and MAPP are presented in Figure 2c. Obviously, the position of the diffraction peaks of APP and MAPP are almost the same, indicating that the crystalline structure of APP is not influenced by cross-linking modification. 


\subsubsection{XPS Analysis}

The XPS spectra of APP and MAPP are shown in Figure 2d. As can be seen, MAPP shows much higher carbon content (44\%), lower contents of oxygen $(32 \%)$, and phosphorus $(8 \%)$ than APP. Furthermore, a new peak appears at $168.1 \mathrm{eV}$ for MAPP, which is ascribed to the $S_{2 p}$ from the intermediate (AEP-ASC). The fitted $\mathrm{N}_{1 S}$ spectra of APP and MAPP are presented in Figure 2e,f. For APP, the binding energy at around $401.2 \mathrm{eV}$ is assigned to $\mathrm{NH}_{4}{ }^{+}$, and the peak at $399.3 \mathrm{eV}$ might correspond to the N (-P-NH-P-). This result of APP spectra agrees with Wang's report [17]. Although the $\mathrm{NH}_{4}{ }^{+}$ peak still appears for MAPP, three new peaks at $399.7 \mathrm{eV}, 400.3 \mathrm{eV}$, and $400.7 \mathrm{eV}$ are observed [16,17]. It indicates that $\mathrm{NH}_{2}{ }^{+}$and $\mathrm{NH}_{3}{ }^{+}$are formed and take place of $\mathrm{NH}_{4}{ }^{+}$partially. This result further confirms the successful ionic interactions between intermediate and APP.

\subsubsection{Surface Morphology and EDS test}

SEM is used to investigate the micro-morphology of the APP and MAPP, and the corresponding images are shown in Figure 3. Apparent changes in the surface morphology between APP and MAPP are easily observed. The pure APP particle shows a smooth surface, and its particle size is about $10 \mu \mathrm{m}$ (Figure 3a,b). However, the MAPP particles look like a cross-linked aggregate of APP particles and display a rough surface (Figure $3 c, d$ ). This could be interpreted as due to H-bonding and ion-dipole forces that contribute to particle aggregation and fusion [16]. The changes in the surface morphology of MAPP are consistent with the proposed model as shown in Figure 1. Moreover, the elemental composition of the APP and MAPP is evaluated from the EDS test (Figure 3e). By comparison with APP, the MAPP presents higher content of C (24.27\%) and lower content of P (11.53\%) as well as the appearance of $S$ element. Both the changes in the surface morphology and element composition between APP and MAPP demonstrate the successful cross-linking modification of APP evidently.
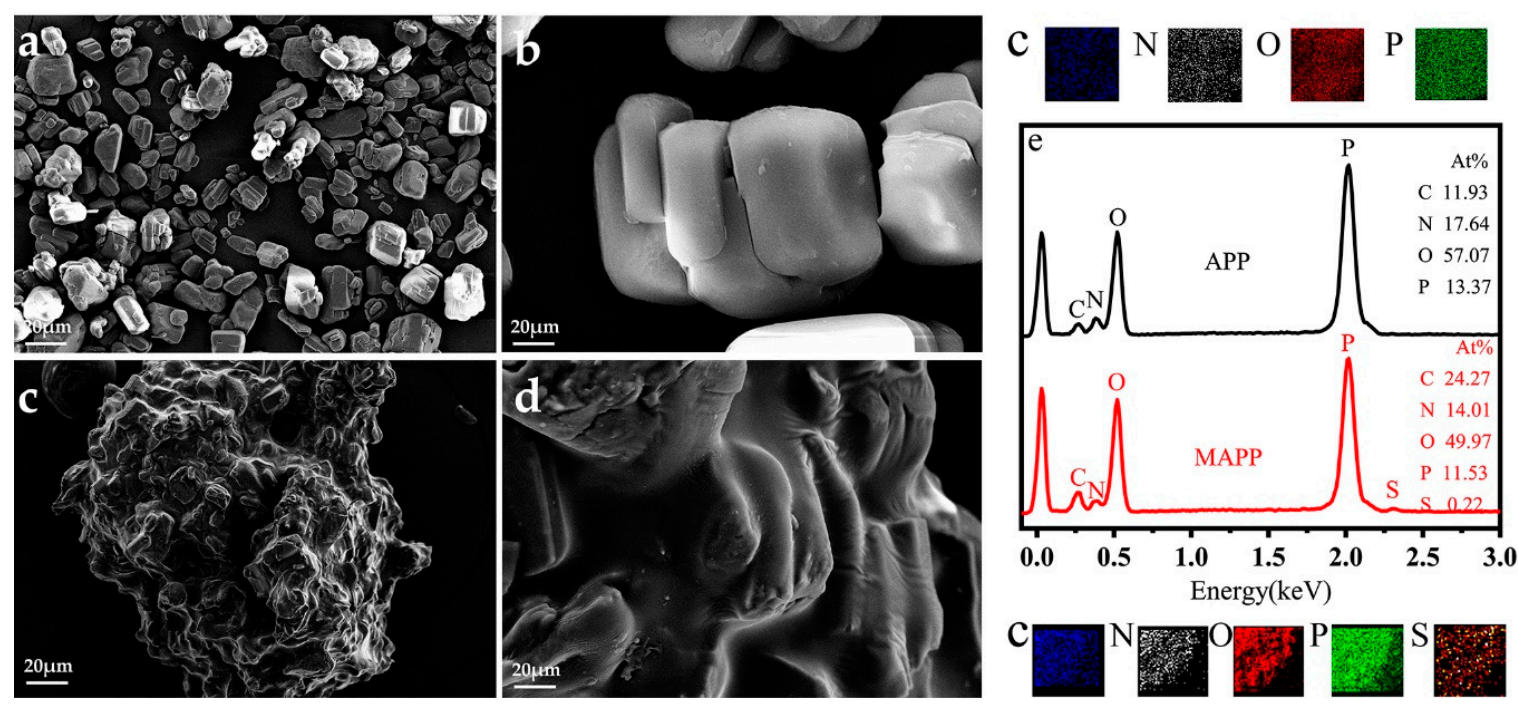

Figure 3. SEM images of (a,b) APP and (c,d) MAPP; (e) EDS image of APP and MAPP.

\subsection{Fire Behavior}

\subsubsection{Reaction to Small Flame (UL 94 Vertical Burning and LOI)}

The flame retardant data of the neat PP and IFR-PP blends are summarized in Table 1 . The neat PP shows serious dripping with no rating level during the UL-94 test, and its value of LOI is merely $17 \%$, indicating its extreme flammability. In the case of the incorporation of APP alone, the PP/APP blend fails to pass the UL-94 V-0 test and gives of LOI value of $19 \%$ even at its loading level up to $25 \mathrm{wt} . \%$, revealing that APP is not very practical to improve the flame retardancy of PP. However, the LOI values 
and flame retardant rating of PP/MAPP blends are increased significantly with the incorporation of MAPP. For example, the IFR-PP blend containing $22.5 \mathrm{wt}$ \% MAPP gives 30\% of LOI value and UL-94 $\mathrm{V}-0$ rating. It demonstrates that the flame retardant efficiency of MAPP is much higher than that of APP for IFR-PP blends.

\subsubsection{Combustion Behavior Under Forced-Flaming Scenario (Cone Calorimetry Test)}

The cone calorimetry test (CCT) is currently the ideal test to assess the burning behavior of polymeric materials under an ongoing fire or forced combustion conditions. The characteristic curves including the heat release rate (HRR), total heat release (THR), smoke production rate (SPR), total smoke production (TSP), $\mathrm{CO}$, and $\mathrm{CO}_{2}$ production $\left(\mathrm{COP}, \mathrm{CO}_{2} \mathrm{P}\right)$ are illustrated in Figure 4 , and some important parameters such as time to ignition (TTI), the peak of heat release rate (PHRR), THR, and average mass loss rates (AMLR) are listed in Table 2.

HRR is generally the most critical performance parameter to characterize the fire intensity, and PHRR indicates the maximum degree of heat release during combustion. As presented in Table 2, the pure PP gives $718.3 \mathrm{~kW} / \mathrm{m}^{2}$ of PHRR value and $57.3 \mathrm{MJ} / \mathrm{m}^{2}$ of THR, which are reduced to $354.7 \mathrm{~kW} / \mathrm{m}^{2}$ and $47.9 \mathrm{MJ} / \mathrm{m}^{2}$ with the incorporation of $25 \mathrm{wt} . \%$ APP, respectively. The corresponding values are further reduced significantly with the substitution of APP with MAPP. For example, the IFR-PP containing $25 \mathrm{wt} . \%$ MAPP presents the lowest PHRR $\left(155.9 \mathrm{~kW} / \mathrm{m}^{2}\right)$ and THR values $\left(44.9 \mathrm{MJ} / \mathrm{m}^{2}\right)$, which are reduced by $78.3 \%$ and $21.6 \%$, respectively, as compared to those of the neat PP. The sharp decline of the PHRR and THR values indicates that MAPP has a more significant role in fire safety than APP.

Fire growth index (FGI) and fire performance index (FPI) are used to assess the fire hazard of polymers, which can be calculated according to the following equation [27] based on the HRR curves and TTI values:

$$
\text { FGI }=\text { PHRR } / T_{\text {PHRR }} \text { FPI }=\text { TTI } / \text { PHRR }
$$

The obtained FGI and FPI values of the neat PP and IFR-PP blends are also listed in Table 2. Generally, the lower FGI and higher FPI values imply higher fire safety properties [28]. As can be seen, the IFR-PP blends display much lower FGI values whilst greater FPI values than that of the pure PP. Noticeably, the FPI value $\left(0.22 \mathrm{~m}^{2} \mathrm{~s} / \mathrm{kW}\right)$ of $\mathrm{PP} / 25 \% \mathrm{MAPP}$ is increased by $57.1 \%$ whilst the FGI value $\left(0.72 \mathrm{~kW} / \mathrm{m}^{2} \mathrm{~s}\right)$ is decreased by $61.5 \%$ as compared with these corresponding values of $\mathrm{PP} / 25 \% \mathrm{APP}$ $\left(0.14 \mathrm{~m}^{2} \mathrm{~s} / \mathrm{kW}\right.$ of FPI and $1.87 \mathrm{~kW} / \mathrm{m}^{2} \mathrm{~s}$ of FGI, respectively). Furthermore, taking the much lower average mass loss rate (AMLR, $0.027 \mathrm{~g} / \mathrm{s}$ ) of PP/25\%MAPP than that $(0.043 \mathrm{~g} / \mathrm{s}$ ) of PP/25\%APP into consideration, it can be concluded that MAPP is superior to APP in fire safety.

It is well known that most victims suffocate to death by inhalation of smoke and $\mathrm{CO}$ in fire accidents. As such, smoke suppression is very significant for flame retardant materials. As can be seen in Table 2, the total smoke production (TSP) is reduced from $48.8 \mathrm{~m}^{2}$ for pure PP to $6.4 \mathrm{~m}^{2}$ for PP/APP while their peaks of the smoke production rate (PSPR) are almost the same. Fascinatingly, both the PSPR and TSP values of $\mathrm{PP} / 25 \% \mathrm{MAPP}$ are reduced drastically as compared with that of the pure PP or $\mathrm{PP} / 25 \% \mathrm{MAPP}$, indicating the superior smoke suppression of MAPP. Moreover, the CO emissions during CCT are ascribed to the insufficient combustion of decomposed volatiles. It is apparent that CO and $\mathrm{CO}_{2}$ relaease of IFR/PP composites are weaker than those of pure PP from Figure 4e,f, which was contributed to the formed char at the early stage and barrier performance of the cross-linking structure of MAPP. It is worth noting that the mean CO yeild $(0.15 \mathrm{~kg} / \mathrm{kg})$ of PP $/ 25 \%$ MAPP specimen is half of that of pure PP $(0.32 \mathrm{~kg} / \mathrm{kg})$ due to the excellent intumescent char residue on the sample surface, implying the possibility of suffocation can be significantly inhibited during evacuation. 
Table 2. Data of the pure PP and its flame-retardant blends during Cone calorimeter combustion.

\begin{tabular}{cccccc}
\hline Sample (Units) & Pure PP & PP/25\%APP & PP/20\%MAPP & PP/22.5\%MAPP & PP/25\%MAPP \\
\hline TTI $(\mathrm{s})$ & 47 & 49 & 40 & 38 & 35 \\
PHRR $\left(\mathrm{kW} / \mathrm{m}^{2}\right)$ & 718.3 & 354.7 & 201.0 & 192.4 & 155.9 \\
T $_{\text {PHRR }}(\mathrm{s})$ & 105 & 190 & 255 & 235 & 215 \\
THR $\left(\mathrm{MJ} / \mathrm{m}^{2}\right)$ & 57.3 & 47.9 & 50.7 & 47.2 & 44.9 \\
TSP $\left(\mathrm{m}^{2}\right)$ & 48.8 & 6.4 & 6.5 & 5.2 & 4.2 \\
Mean COY $(\mathrm{kg} / \mathrm{kg})$ & 0.32 & 0.11 & 0.17 & 0.17 & 0.15 \\
PSPR $\left(\mathrm{m}^{2} / \mathrm{s}\right)$ & 0.5 & 0.045 & 0.026 & 0.024 & 0.016 \\
AMLR $(\mathrm{g} / \mathrm{s})$ & 0.059 & 0.043 & 0.033 & 0.032 & 0.027 \\
FPI $\left(\mathrm{m}^{2} \mathrm{~s} / \mathrm{kW}\right)$ & 0.07 & 0.14 & 0.20 & 0.20 & 0.22 \\
FGI $\left(\mathrm{kW} / \mathrm{m}^{2} \mathrm{~s}\right)$ & 6.84 & 1.87 & 0.79 & 0.82 & 0.72 \\
\hline
\end{tabular}
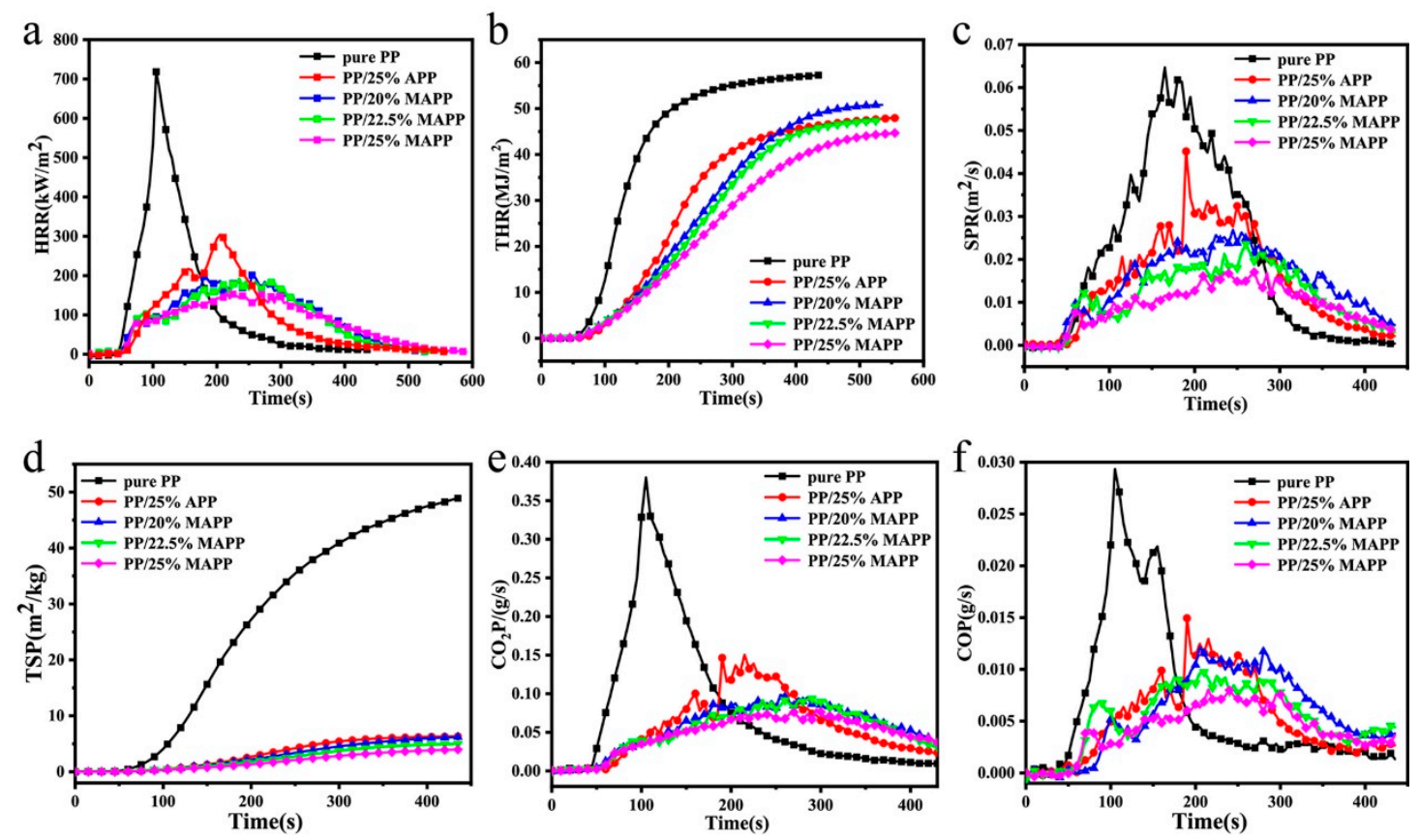

Figure 4. $\operatorname{HRR}(\mathbf{a}), \mathrm{THR}(\mathbf{b}), \operatorname{SPR}(\mathbf{c}), \mathrm{TSP}(\mathbf{d}), \mathrm{CO}_{2} \mathrm{P}(\mathbf{e})$, and $\mathrm{COP}(\mathbf{f})$ curves of samples during the combustion in CCT.

\subsection{Thermal Stability Analysis}

Figures 5 and 6 present the TG and DTG curves of the flame retardants and IFR-PP samples under nitrogen and air atmosphere, respectively. Corresponding data, such as the initial thermal decomposition temperature $\left(T_{5 w t} \%\right)$, the temperature at maximal degradation $\left(T_{\max }\right)$, Rate of $T_{\max }$, and char residue at $800^{\circ} \mathrm{C}$ are listed in Tables 3 and 4 . It can be observed that the MAPP shows high $T_{5 w t} \%$ values, no matter under the nitrogen $\left(303.1^{\circ} \mathrm{C}\right)$ or air $\left(270.9^{\circ} \mathrm{C}\right)$ atmosphere, which fully meets the melt blending temperature of $\mathrm{PP}\left(190^{\circ} \mathrm{C}\right)$. While APP presents two primary mass loss processes, ascribing to thermal removal of $\mathrm{H}_{2} \mathrm{O}$ and $\mathrm{NH}_{3}$, and crosslinking reactions between phosphorus-containing acid. It is noticeable that thermal decomposition process of MAPP is little different from APP, due to the introduction of AEP-ASC. The deamination, dehydration and decomposition of ASC at around 225-380 ${ }^{\circ} \mathrm{C}$ make the first DTG peak become wider. The second stage after $500{ }^{\circ} \mathrm{C}$ corresponds to the pyrolysis of APP chains as well. Furthermore, the pure PP shows a single degradation process with the $T_{5 w t}$ and $T_{\max }$ at $373.5^{\circ} \mathrm{C}$ and $455.4{ }^{\circ} \mathrm{C}$ under nitrogen atmosphere. Moreover, there is no char residue left at $800^{\circ} \mathrm{C}$ no matter whether under nitrogen or air atmosphere, indicating pure PP fails to form char alone. On the contrary, two-stage degradation is observed for all IFR-PP blends. The first-stage at low temperature is mainly ascribed to the degradation of the IFR and PP, and the 
second-stage at high temperature is attributed to the decomposition products (polyphosphoric acids, pyrophosphate, and metaphosphate acid) of APP or MAPP [1]. Furthermore, all samples display a lower degradation temperature under the air atmosphere than that under the nitrogen atmosphere owing to thermo-oxidative degradation [24]. As compared with the pure PP, all PP/APP samples display greater $T_{5 w t \%}$ values, which is ascribed to the protection of the thick polyphosphoric acid fluid produced by the decomposition of APP [25]. In the case of substitution of APP with MAPP, the $T_{5 w t} \%$ values of PP/MAPP samples move to lower temperatures since the $T_{5 w t} \%$ of MAPP is lower than that of APP. It is noteworthy that the char residue of $\mathrm{PP} / 25 \% \mathrm{MAPP}$ is up to $5.4 \%$ at $800{ }^{\circ} \mathrm{C}$ under the air atmosphere, which is higher than that of pure PP and PP/APP samples. Such an observation demonstrates that the phosphoric acid released by APP can catalyze the carbon formation of the piperazine ring from AEP and the physical carbon formation of the benzene ring in ASC make MAPP itself can form a stable carbon layer, which acts as a barrier between oxygen and PP matrix [11].
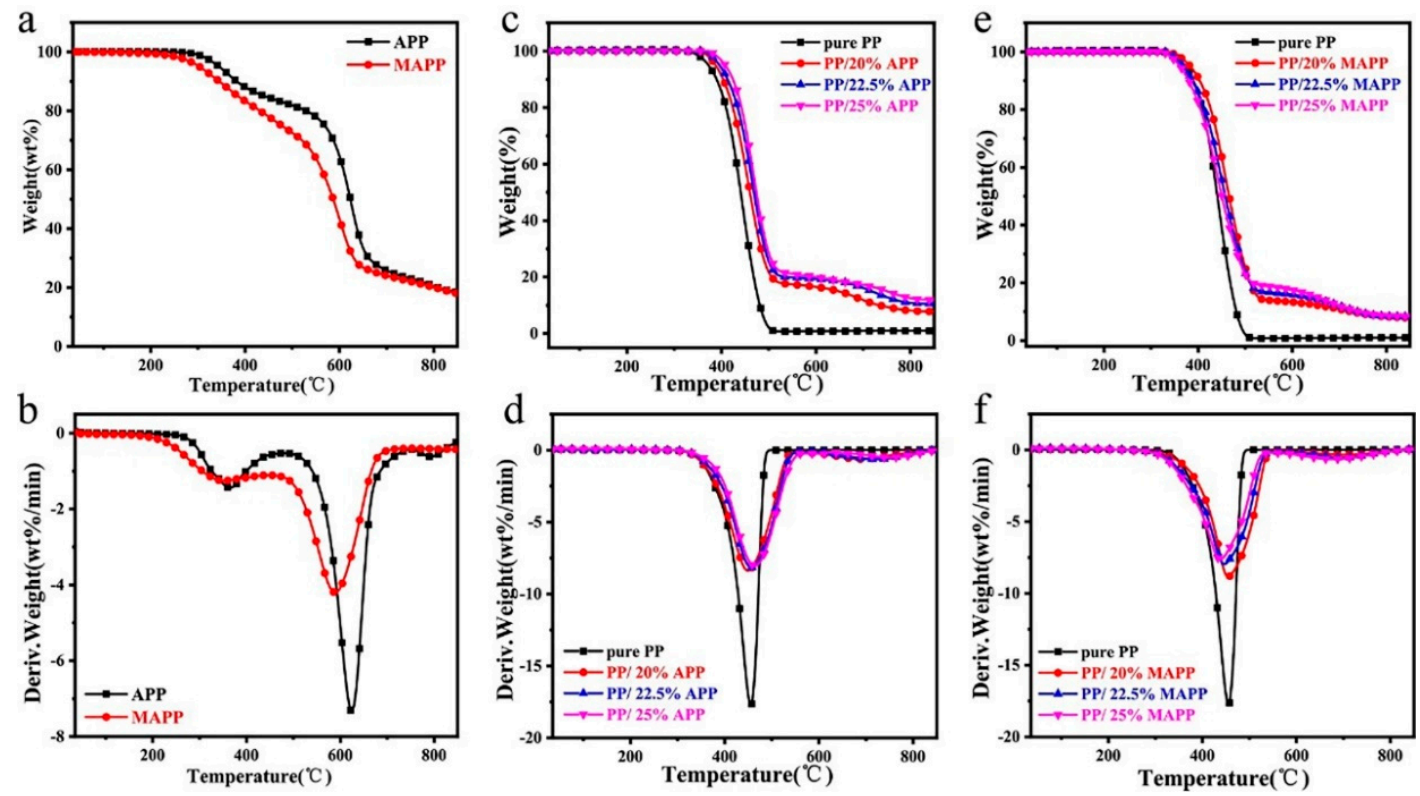

Figure 5. (a) TG and (b) DTG curves of APP and MAPP. (c,e) TG and (d,f) DTG curves of PP and its flame-retardant blends under the nitrogen atmosphere.

Table 3. TGA data of the IFR-PP samples under nitrogen atmosphere.

\begin{tabular}{|c|c|c|c|c|c|}
\hline Sample & $T_{5 w t \%}\left({ }^{\circ} \mathrm{C}\right)$ & $T_{\max 1}\left({ }^{\circ} \mathrm{C}\right)$ & $T_{\max 2}\left({ }^{\circ} \mathrm{C}\right)$ & $\begin{array}{c}\text { Rate of } T_{\max 1} \\
\text { (wt. } \% / \mathrm{min})\end{array}$ & $\begin{array}{c}800{ }^{\circ} \mathrm{C} \\
\text { Char Residues (\%) }\end{array}$ \\
\hline APP & 345.1 & 364.4 & 623.9 & 7.3 & 20.5 \\
\hline MAPP & 303.1 & 351.7 & 588.4 & 4.2 & 20.1 \\
\hline pure PP & 373.5 & 455.4 & / & 17.7 & 0 \\
\hline PP/20\%APP & 387.4 & 448.8 & 687.9 & 8.4 & 8.1 \\
\hline $\mathrm{PP} / 22.5 \% \mathrm{APP}$ & 395.9 & 456.6 & 719.1 & 8.2 & 10.9 \\
\hline $\mathrm{PP} / 25 \% \mathrm{APP}$ & 407.9 & 463.7 & 747.4 & 8.1 & 12.5 \\
\hline PP/20\%MAPP & 383.0 & 454.6 & 704.6 & 8.8 & 8.3 \\
\hline PP/22.5\%MAPP & 368.0 & 446.1 & 694.8 & 8.0 & 8.5 \\
\hline PP/25\%MAPP & 361.2 & 437.6 & 670.9 & 7.6 & 8.6 \\
\hline
\end{tabular}



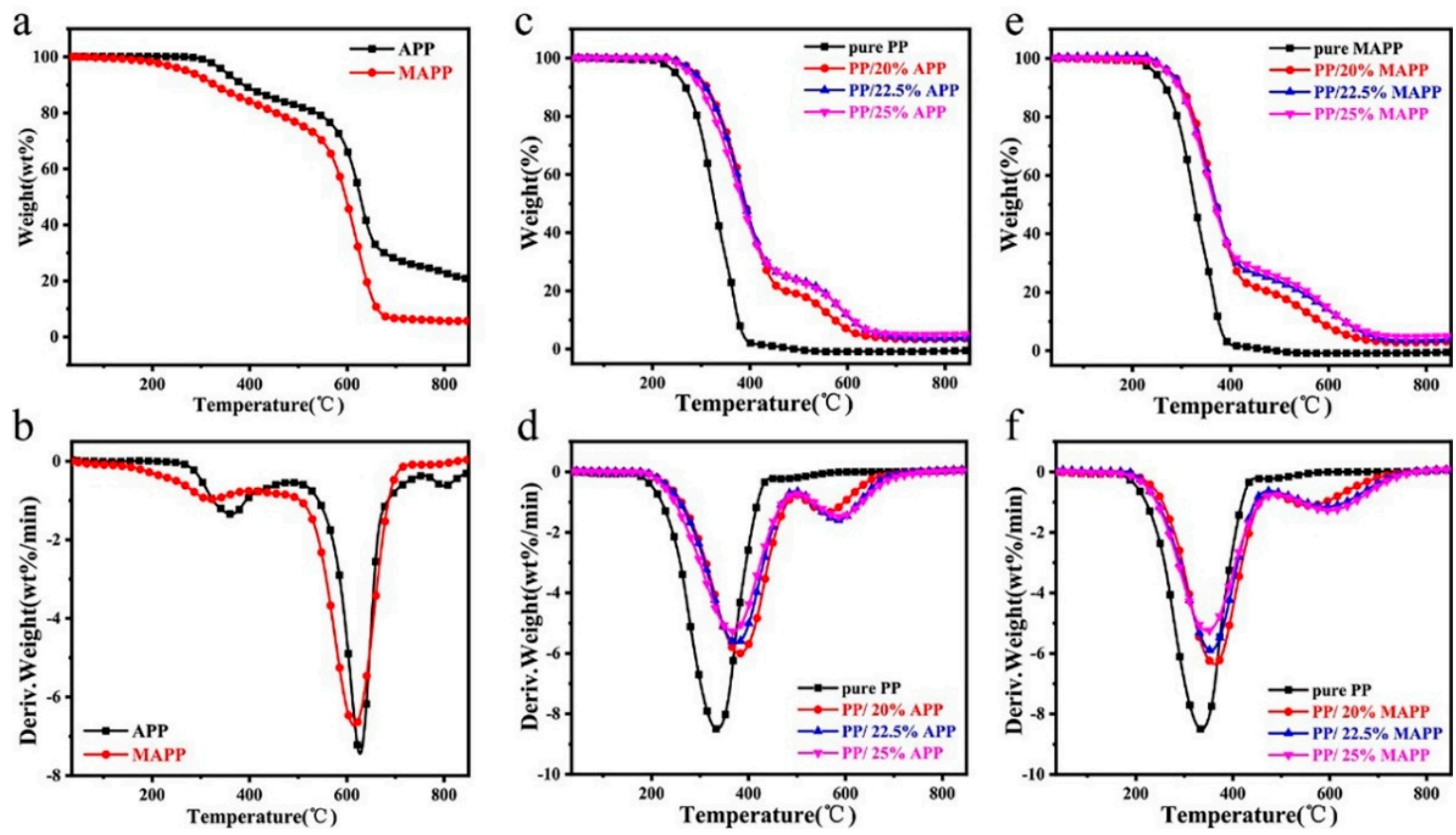

Figure 6. (a) TG and (b) DTG curves of APP and MAPP. (c,e) TG and (d,f) DTG. curves of PP and its flame-retardant blends under the air atmosphere.

Table 4. Data of TGA for PP and its flame-retardant blends under air atmosphere.

\begin{tabular}{|c|c|c|c|c|c|}
\hline Sample & $T_{5 w t \%}\left({ }^{\circ} \mathrm{C}\right)$ & $T_{\max 1}\left({ }^{\circ} \mathrm{C}\right)$ & $T_{\max 2}\left({ }^{\circ} \mathrm{C}\right)$ & $\begin{array}{l}\text { Rate of } T_{\max 1} \\
\text { (wt. } \% / \mathrm{min})\end{array}$ & $\begin{array}{c}800{ }^{\circ} \mathrm{C} \\
\text { Char Residues (\%) }\end{array}$ \\
\hline APP & 346.6 & 359.5 & 626.8 & 7.4 & 22.9 \\
\hline MAPP & 270.9 & 320.7 & 615.0 & 6.7 & 5.7 \\
\hline pure PP & 246.4 & 334.8 & / & 8.5 & 0 \\
\hline PP/20\%APP & 287.9 & 381.1 & 561.3 & 6.0 & 3.7 \\
\hline $\mathrm{PP} / 22.5 \% \mathrm{APP}$ & 284.2 & 374.1 & 583.7 & 5.7 & 3.9 \\
\hline PP/25\%APP & 275.0 & 366.0 & 589.9 & 5.3 & 5.3 \\
\hline PP/20\%MAPP & 279.3 & 362.1 & 557.1 & 6.4 & 3.3 \\
\hline $\mathrm{PP} / 22.5 \% \mathrm{MAPP}$ & 277.3 & 354.1 & 591.0 & 5.9 & 4.1 \\
\hline $\mathrm{PP} / 25 \% \mathrm{MAPP}$ & 273.8 & 346.0 & 596.6 & 5.6 & 5.4 \\
\hline
\end{tabular}

\subsection{Flame-Retardant Mechanism Analysis}

\subsubsection{Gas Phase Analysis}

A TG-FTIR test was performed to analyze the volatile gases released from IFR-PP samples, which helps to explore the flame-retardant mechanism of the gas phase. Figure 7 illustrates the FTIR curves and 3D spectra of the evolved gaseous products during the pyrolysis of pure $\mathrm{PP}, \mathrm{PP} / 25 \% \mathrm{APP}$, and $\mathrm{PP} / 25 \%$ MAPP. All the samples display the following characteristic peaks: alkanes $\left(2960,2920 \mathrm{~cm}^{-1}\right)$, alkenes $\left(1647,1465\right.$, and $\left.1371 \mathrm{~cm}^{-1}\right)$ and a diene $\left(890 \mathrm{~cm}^{-1}\right)$ [10]. However, the intensity of the abovementioned peaks in the spectra of $\mathrm{PP} / 25 \% \mathrm{MAPP}$ is weaker than that of the pure PP and $\mathrm{PP} / 25 \% \mathrm{APP}$, suggesting that volatile components are effectively suppressed during the degradation process of $\mathrm{PP} / 25 \% \mathrm{MAPP}$ specimens [21]. As compared with the pure PP, both $\mathrm{PP} / 25 \% \mathrm{APP}$ and $\mathrm{PP} / 25 \%$ MAPP specimens show characteristic peaks ascribed to $\mathrm{P}=\mathrm{O}\left(1258 \mathrm{~cm}^{-1}\right), \mathrm{P}-\mathrm{O}\left(1087 \mathrm{~cm}^{-1}\right)$, and $\mathrm{NH}_{3}\left(966\right.$ and $937 \mathrm{~cm}^{-1}$ ), which contribute to the thermal degradation of APP and scission of polyphosphoric acids [29]. Furthermore, it is noticeable that a new peak at $1499 \mathrm{~cm}^{-1}\left(\mathrm{SO}_{2}\right)$ is found only in the spectrum of the $\mathrm{PP} / 25 \% \mathrm{MAPP}$ specimen [22,30]. The appearance of these non-combustible gases $\left(\mathrm{NH}_{3}\right.$ and $\left.\mathrm{SO}_{2}\right)$ can dilute the released combustible gases (hydrocarbons, etc.). 

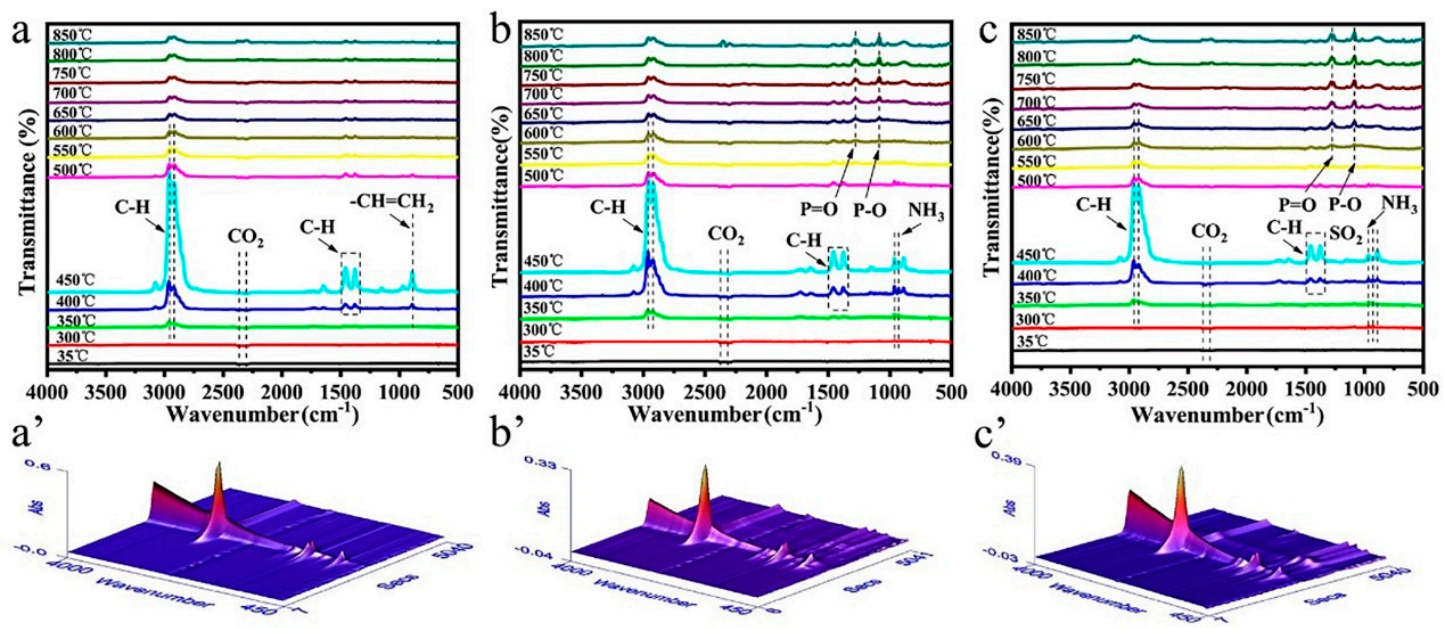

Figure 7. FTIR spectra and 3D images of the pyrolysis products of pure PP $\left(\mathbf{a}, \mathbf{a}^{\prime}\right), \operatorname{PP} / 25 \% \mathrm{APP}\left(\mathbf{b}, \mathbf{b}^{\prime}\right)$, and $\mathrm{PP} / 25 \% \mathrm{MAPP}\left(\mathbf{c}, \mathbf{c}^{\prime}\right)$ at different temperatures.

\subsubsection{Analysis of Char Residue}

Digital photographs of the residues after CCT are shown in Figure 8. Obviously, there is no residue left for pure PP and a minute quantity of residues for PP/25\%APP. This indicates that the incorporation of the unmodified APP alone cannot promote the formation of an expanded char layer. However, more intumescent and expanded char residues with expansion heights of $1.7 \mathrm{~cm}$ (Figure $8 \mathrm{c}^{\prime}$ ) and $2.5 \mathrm{~cm}$ (Figure $8 \mathrm{~d}^{\prime}$ ) are observed for $\mathrm{PP} / 22.5 \% \mathrm{MAPP}$ and $\mathrm{PP} / 25 \% \mathrm{MAPP}$, respectively. The expansion height is usually adopted to assess the swelling degree or quality of the char layer. Accordingly, it is concluded that MAPP has a greater effect on the formation of the intumescent char layer than the unmodified APP, which can obstruct the heat and mass transfer between the gas and condensed phase.
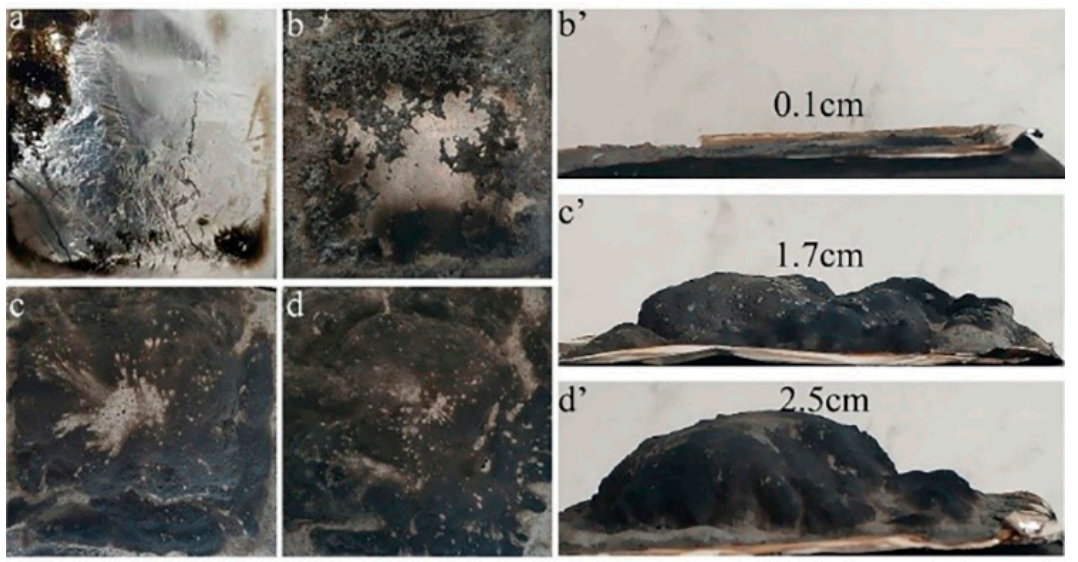

Figure 8. Digital photographs of residues of pure PP (a), PP/25\%APP (b, b' $\left.\mathbf{b}^{\prime}\right), \mathrm{PP} / 22.5 \% \mathrm{MAPP}\left(\mathbf{c}, \mathbf{c}^{\prime}\right)$, and PP/25\%MAPP (d, d') samples after CCT.

The microstructure of the residues after CCT was observed further via SEM, and the resultant images are presented in Figure 9. Clearly, numerous large holes are observed both in the outer and inner char residues of $\mathrm{PP} / 25 \% \mathrm{APP}$ whilst compact and continuous char layer is observed on the surface of PP/MAPP blends. Especially, the appearance of some char bubbles in the PP/25\%MAPP surface residues indicates that the incorporation of MAPP enhances the compactness of char residues and thus forms a much excellent IFR system [5]. However, the honeycomb structure still exists in the inner char residue of PP/MAPP samples, which is ascribed to the diffusion of pyrolysis gas. 

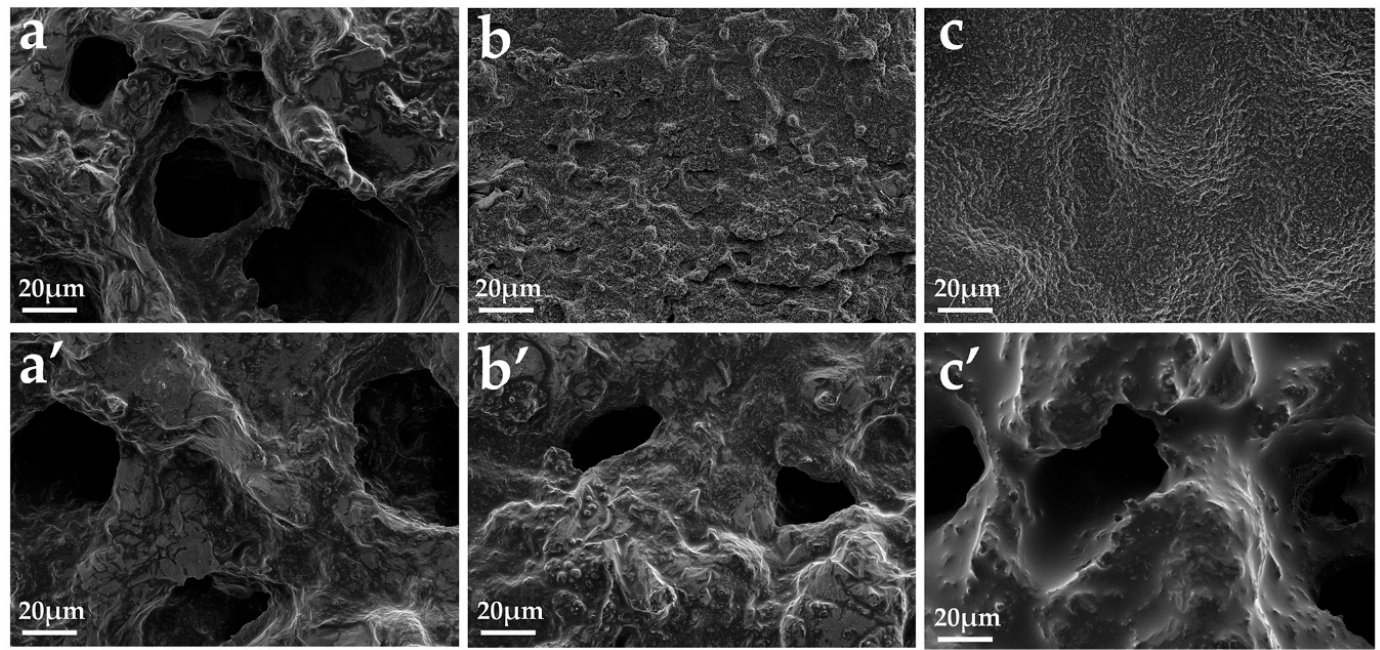

Figure 9. SEM images of char residues of $\mathrm{PP} / 25 \% \mathrm{APP}\left((\mathbf{a})\right.$ outer, $\left(\mathbf{a}^{\prime}\right)$ inner $), \mathrm{PP} / 22.5 \% \mathrm{MAPP}(\mathbf{( b )}$ outer, (b') inner), and PP/25\%MAPP ((c) outer, (c') inner) after CCT.

The elemental compositions of the char residue of the PP/25\%MAPP sample after CCT were investigated by the XPS analysis (Figure 10). As can be seen, the main elements in the residue are C, O, $\mathrm{P}$, and N. In $\mathrm{N}_{1 \mathrm{~S}}$ spectra (Figure 10b), the peaks at $400.5 \mathrm{eV}, 401.2 \mathrm{eV}$, and $402.3 \mathrm{eV}$ are attributed to $\mathrm{P}-\mathrm{N}-\mathrm{P}, \mathrm{NH}_{4}{ }^{+}$, and $\mathrm{P}-\mathrm{C}-\mathrm{N}$, respectively $[21,23]$. The $\mathrm{O}_{1 \mathrm{~S}}$ peaks (Figure $10 \mathrm{c}$ ) at $531.1 \mathrm{eV}$ and $532.2 \mathrm{eV}$ are assigned to $=\mathrm{O}$ (including $\mathrm{P}=\mathrm{O}$ and $\mathrm{C}=\mathrm{O}$ ) and $-\mathrm{O}-$ (including $\mathrm{C}-\mathrm{O}-\mathrm{C}$ and $\mathrm{P}-\mathrm{O}-\mathrm{C}$ [10]), respectively. In the case of $\mathrm{P}_{2 \mathrm{P}}$ spectra (Figure 10d), the peaks around $133.9 \mathrm{eV}$ and $134.5 \mathrm{eV}$ correspond to $\mathrm{P}=\mathrm{O}$ and $\mathrm{P}-\mathrm{O}-\mathrm{C}$ structure, respectively $[22,31]$. The results above demonstrate that the existence of $\mathrm{P}-\mathrm{C}-\mathrm{N}$ and $\mathrm{P}-\mathrm{O}-\mathrm{C}$ structure plays a vital role in forming a dense and continuous char layer.
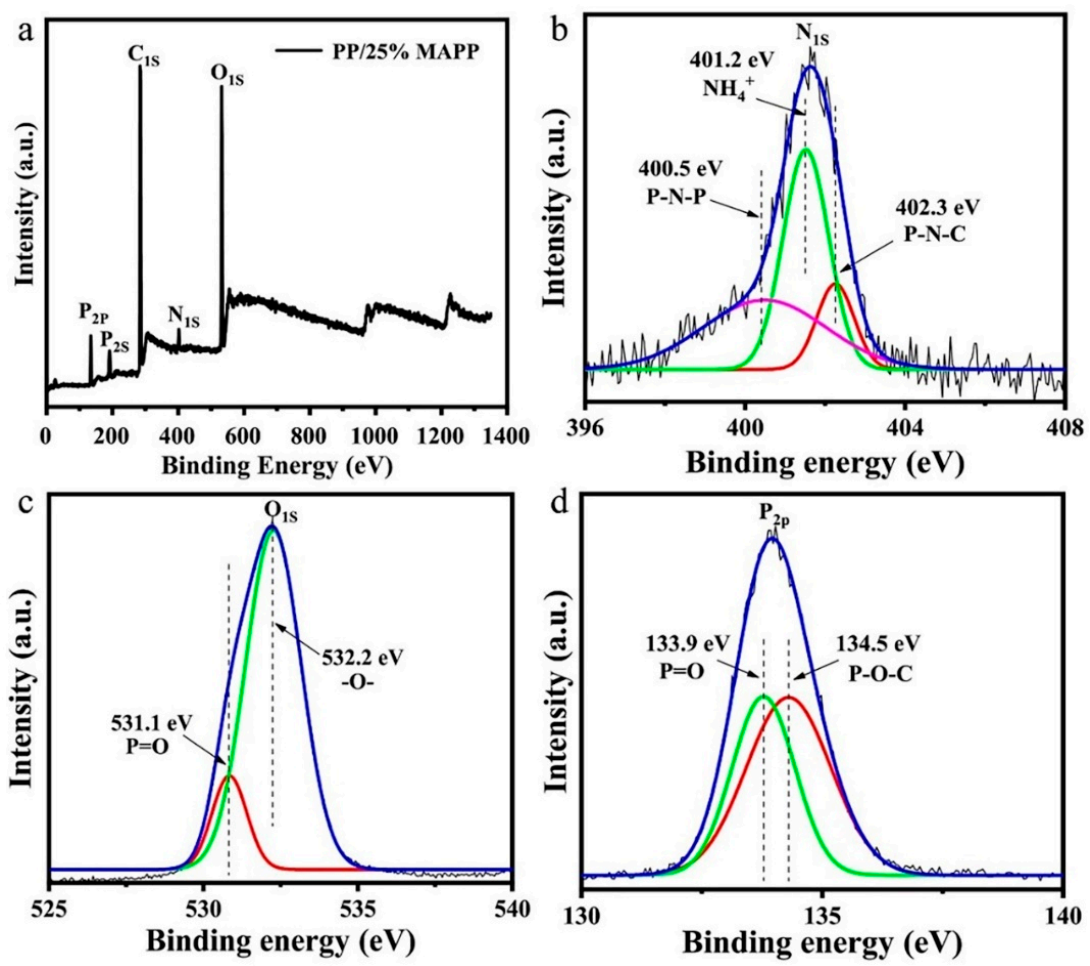

Figure 10. The wide-scan (a), $\mathrm{N}_{1 \mathrm{~S}}(\mathbf{b}), \mathrm{O}_{1 \mathrm{~S}}(\mathbf{c})$, and $\mathrm{P}_{2 \mathrm{P}}$ (d) XPS spectra of char residue of $\mathrm{PP} / 25 \% \mathrm{MAPP}$ after CCT. 
Raman spectroscopy is a useful tool to characterize the degree of graphitization of char residues. The Raman spectra are mainly divided into $\mathrm{G}$ bands (about $1590 \mathrm{~cm}^{-1}$, showing the graphitic structure) and $\mathrm{D}$ bands (about $1365 \mathrm{~cm}^{-1}$, representing lattice defects of carbon atom). Furthermore, the degree of graphitization of the char residue can be assessed by the area ratio of two peaks $\left(A_{D} / A_{G}\right)$. Generally, the lower ratio of $A_{D} / A_{G}$ means the higher graphitization degree and better thermal-oxidative stability of the char [32,33]. As shown in Figure 11, the $A_{D} / A_{G}$ values are calculated to be 2.57 for $P P / 25 \% A P P$, 2.24 for $\mathrm{PP} / 22.5 \% \mathrm{MAPP}$, and 2.12 for $\mathrm{PP} / 25 \% \mathrm{MAPP}$, respectively. As such, it is concluded that the incorporation of MAPP facilitates the graphitization to form much dense and continuous surface char layers, which is in agreement with the SEM observation results.
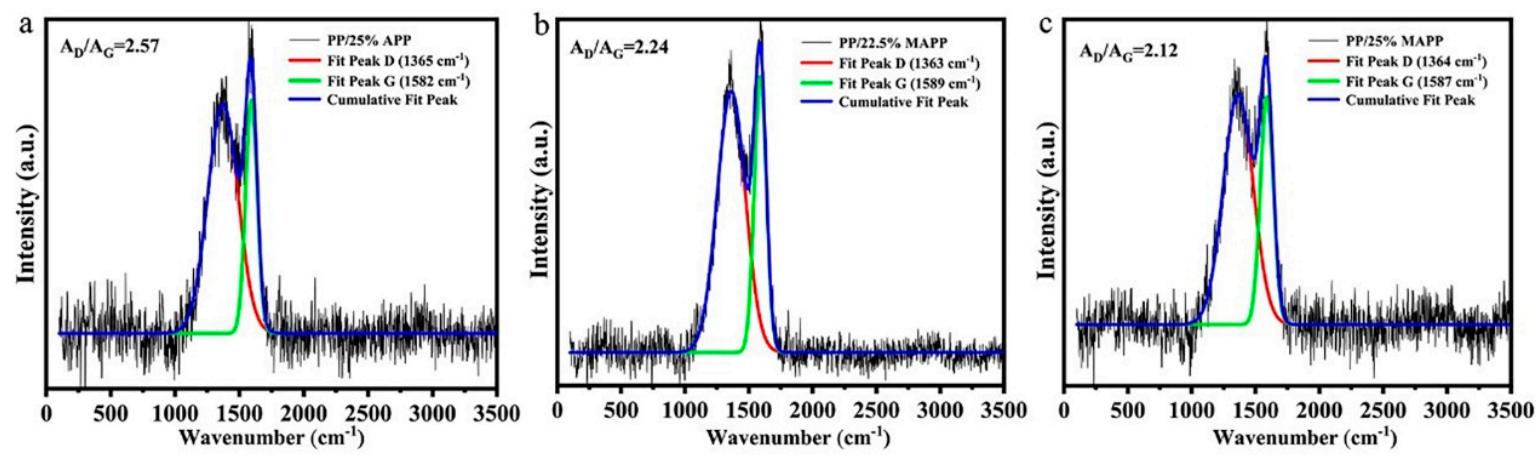

Figure 11. Raman spectra of char residues of (a) PP/25\%APP, (b) PP/22.5\%MAPP, (c) PP/25\%MAPP after CCT.

\subsubsection{Possible Flame-Retardant Mechanism}

Based on the analysis of the volatile gas and char residues, a possible flame-retardant mechanism is proposed and illustrated in Figure 12. In the initial stage of the combustion, the dehydration of MAPP and the cleavage of ionic bonds result to release of some incombustible gases (such as $\mathrm{NH}_{3}$, $\mathrm{SO}_{2}$, and water vapor) which can fully dilute the oxygen and heat. With rising temperature, MAPP is thermally decomposed into polyphosphoric acid, pyrophosphoric acid, or metaphosphoric, all of which can esterify and crosslink with the char precursor (piperazine ring) [10]. Moreover, the phosphate ester radicals and pyrophosphate radicals released from the decomposition of MAPP readily quench $\mathrm{O} \cdot, \mathrm{H} \cdot$, and $\mathrm{OH}$. radicals [34]. Additionally, the benzene ring in the intermediate acts as both the cross-linking agent and crystal core [23]. As such, the char layer containing $\mathrm{P}-\mathrm{O}-\mathrm{C}$ and $\mathrm{P}-\mathrm{C}-\mathrm{N}$ structure is formed and its quality is improved owing to the crosslinking networks. It is noteworthy that although the initially formed char layer did not swell, its continuous and compact structure hinders the gas overflowing and the accumulation of the incombustible gases keeps the char layer expanding. As a result, an intumescent and dense char layer is formed, which protects the underlying substrate from further thermal decomposition. The physical (expansion and morphology) and chemical (thermal stability) properties of the char layer were enhanced after introducing MAPP and the possible IFR mechanism is shown in Figure 12 [21].

\subsection{Mechanical Properties}

Figure 13 illustrates the typical stress-strain curves of pure PP and IFR-PP blends, and the mechanical properties data are provided in Table 5. The pure PP gives 39.1 MPa of tensile strength, $147.1 \%$ of elongation at break, and $4.6 \mathrm{~kJ} \times \mathrm{m}^{-2}$ of impact strength, respectively. Although the mechanical properties of IFR-PP blends are decreased to a certain extent by comparison with the pure $\mathrm{PP}$, the $\mathrm{PP} / 25 \% \mathrm{MAPP}$ sample shows better mechanical properties than the PP/25\%APP. Namely, the tensile strength, elongation at break, and impact strength of PP/25\%MAPP are increased by $12.3 \%$, $110.5 \%$, and $37.9 \%$ as compared with $\mathrm{PP} / 25 \% \mathrm{APP}$, respectively. This difference might be related to interface interaction between the dispersion phase (MAPP or APP) and the PP matrix. Figure 14 presents 
the SEM images of the impact fractured surface of $\mathrm{PP}, \mathrm{PP} / 25 \% \mathrm{APP}$, and $\mathrm{PP} / 25 \% \mathrm{MAPP}$. APP particles fail to adhere to the PP matrix, and the interface between the APP particles and PP matrix is clearly visible (Figure 14b). Conversely, the MAPP particles are uniformly embedded in the PP matrix (Figure 14c), which leads to an improvement of the elongation at break and impact strength. This observation is probably ascribed to that the modification of APP improved the interfacial adhesion, and the addition of MAPP had little effect on the mechanical properties of IFR-PP samples.

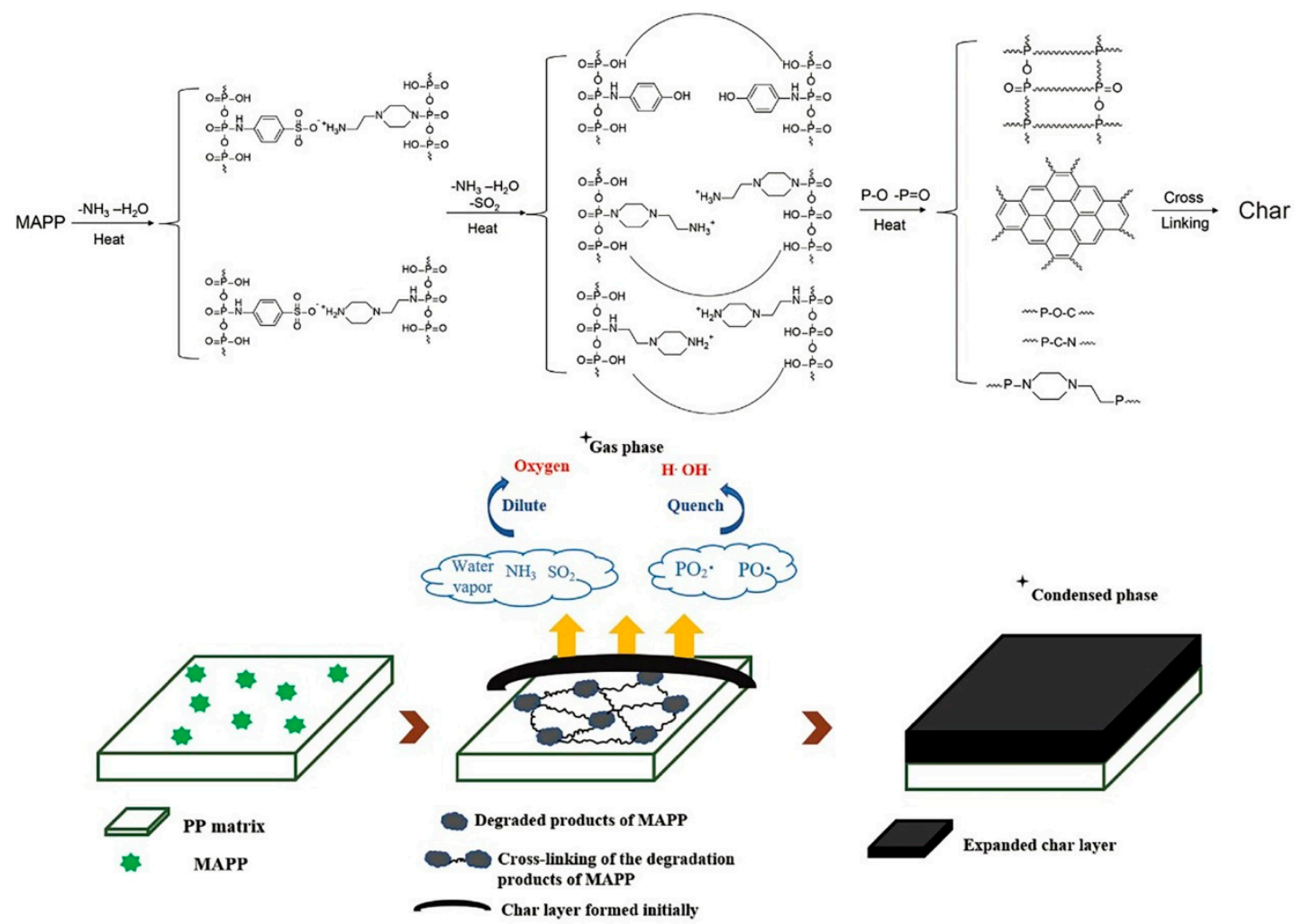

Figure 12. Schematic diagram of the flame-retardant mechanism.

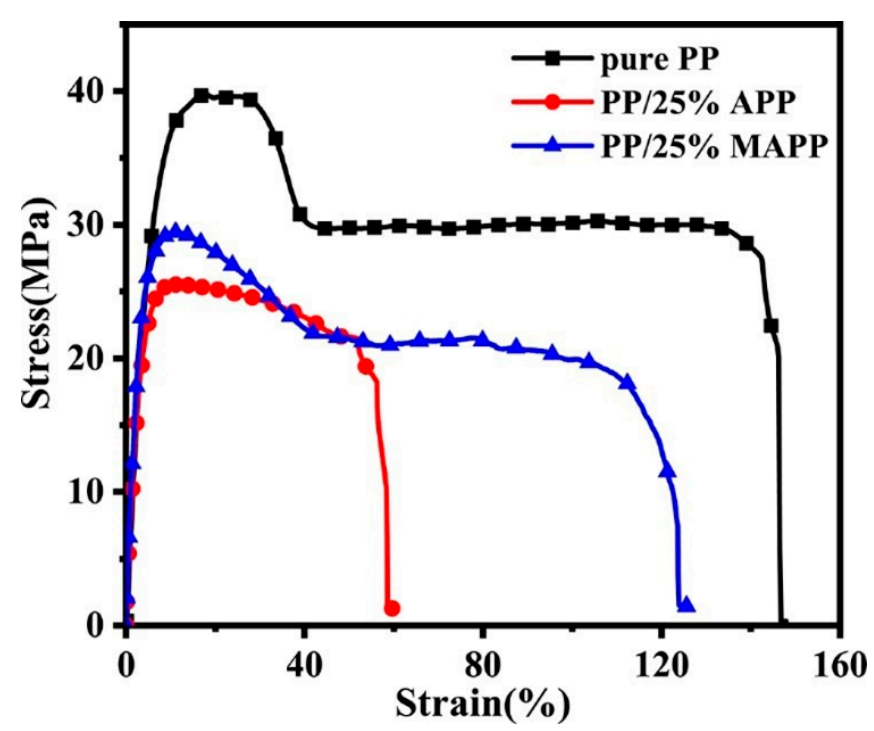

Figure 13. Typical stress-strain curves of pure PP and its flame-retardant blends. 
Table 5. Mechanical properties data of pure PP and its flame-retardant blends.

\begin{tabular}{cccc}
\hline Sample & $\begin{array}{c}\text { Tensile Strength } \\
\mathbf{( M P a )}\end{array}$ & $\begin{array}{c}\text { Elongation at Break } \\
\mathbf{( \% )}\end{array}$ & $\begin{array}{c}\text { Impact Strength } \\
\left(\mathbf{k J ~ m}^{-\mathbf{2}} \mathbf{)}\right.\end{array}$ \\
\hline Pure PP & $39.1 \pm 0.4$ & $147.1 \pm 3.0$ & $4.6 \pm 0.5$ \\
PP/25\%APP & $25.3 \pm 2.5$ & $59.8 \pm 6.8$ & $2.9 \pm 0.2$ \\
PP/25\%MAPP & $28.4 \pm 1.1$ & $125.9 \pm 4.8$ & $4.0 \pm 0.2$ \\
\hline
\end{tabular}
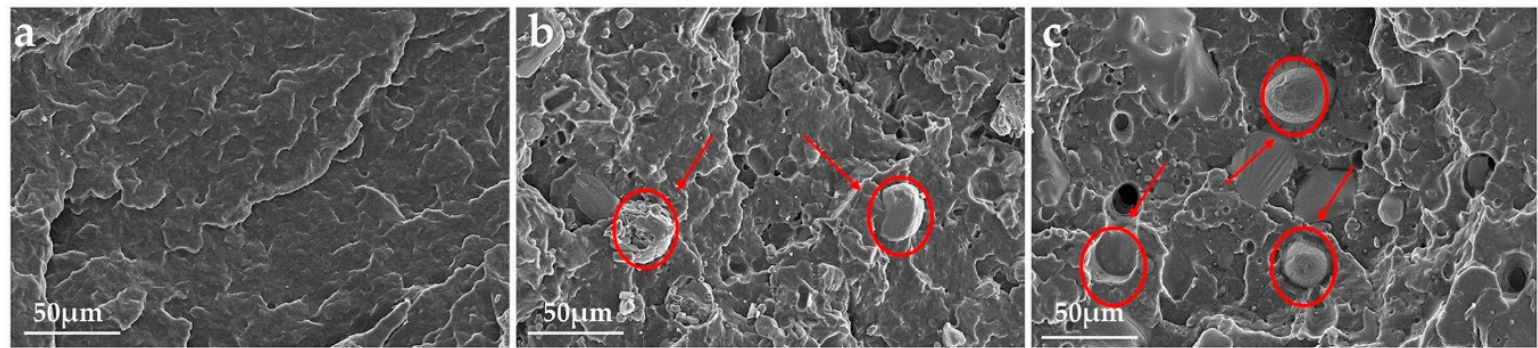

Figure 14. SEM images of the impact fractured surface of pure PP (a), $\mathrm{PP} / 25 \% \mathrm{APP}(\mathbf{b})$, and PP/25\%MAPP (c).

\section{Conclusions}

A novel mono-component flame retardant (MAPP) was prepared by the modification of conventional APP with piperazine sulfonate. The MAPP showed more effective flame retardancy and smoke suppression than the traditional APP. The PP/MAPP composite passed the UL-94 V-0 rating and achieved $30 \%$ of LOI value at $22.5 \mathrm{wt} \%$ loading level of MAPP. The HRR, PHRR, and TSP values of $\mathrm{PP} / 22.5 \% \mathrm{MAPP}$ were reduced significantly as compared with those of the pure PP or PP/25\%MAPP. The results of TGA-FTIR and char residue analysis revealed that some incombustible gases were released and intumescent, dense and continuous char residues were produced with the incorporation of MAPP. The PP $/ 25 \% \mathrm{MAPP}$ sample also displayed better mechanical properties than the $\mathrm{PP} / 25 \% \mathrm{APP}$.

Author Contributions: B.W. and Z.L. designed the research objective. Y.P. performed experiments and analyzed the results. All the authors reviewed and provided feedback on the submitted article. All authors have read and agreed to the published version of the manuscript.

Funding: This work was supported financially by the Natural Science Foundation of Jiangsu Province (BK20130249).

Acknowledgments: This work was supported financially by the Natural Science Foundation of Jiangsu Province (BK20130249) and Postgraduate Research \& Practice Innovation Program of Jiangsu Province (SJCX20-0979).

Conflicts of Interest: The authors declare no competing financial interest.

\section{References}

1. Zhao, Z.; Jin, Q.; Zhang, N.; Guo, X.; Yan, H. Preparation of a novel polysiloxane and its synergistic effect with ammonium polyphosphate on the flame retardancy of polypropylene. Polym. Degrad. Stab. 2018, 150, 73-85. [CrossRef]

2. Yang, K.; Xu, M.J.; Li, B. Synthesis of N-ethyl triazineepiperazine copolymer and flame retardancy and water resistance of intumescent flame retardant polypropylene. Polym. Degrad. Stab. 2013, 98, 1397-1406. [CrossRef]

3. Qi, H.S.; Liu, S.W.; Chen, X.L.; Shen, C.H.; Gao, S.J. The flame retardant and thermal performances of polypropylene with a novel intumescent flame retardant. J. Appl. Polym. Sci. 2020, 137, 49047. [CrossRef]

4. Qi, C.; Yuan, B.; Dong, H.; Li, K.; Shang, S.; Sun, Y.; Chen, G.; Zhan, Y. Supramolecular self-assembly modification of ammonium polyphosphate and its flame retardant application in polypropylene. Polym. Adv. Technol. 2020, 31, 1099-1109. [CrossRef]

5. Yu, G.; Ma, C.; Li, J. Flame retardant effect of cytosine pyrophosphate and pentaerythritol on polypropylene. Compos. B Eng. 2020, 180, 107520. [CrossRef] 
6. Rault, F.; Giraud, S.; Salaün, F.; Almeras, X. Development of a Halogen Free Flame Retardant Masterbatch for Polypropylene Fibers. Polymers 2015, 7, 220-234. [CrossRef]

7. Seidi, F.; Movahedifar, E.; Naderi, G.; Akbari, V.; Ducos, F.; Shamsi, R.; Vahabi, H.; Saeb, M.R. Flame Retardant Polypropylenes: A Review. Polymers 2020, 12, 1701. [CrossRef]

8. Tang, W.; Qian, L.; Chen, Y.; Qiu, Y.; Xu, B. Intumescent flame retardant behavior of charring agents with different aggregation of piperazine/triazine groups in polypropylene. Polym. Degrad. Stab. 2019, 169, 108982. [CrossRef]

9. Ding, S.; Liu, P.; Zhang, S.; Ding, Y.; Wang, F.; Gao, C.; Yang, M. Preparation and characterization of cyclodextrin microencapsulated ammonium polyphosphate and its application in flame retardant polypropylene. J. Appl. Polym. Sci. 2020, 137, 49001. [CrossRef]

10. Zhang, N.; Zhang, J.; Yan, H.; Guo, X.; Sun, Q.; Guo, R. A novel organic-inorganic hybrid K-HBPE@APP performing excellent flame retardancy and smoke suppression for polypropylene. J. Hazard. Mater. 2019, 373, 856-865. [CrossRef]

11. Zhang, T.; Tao, Y.; Zhou, F.; Sheng, H.; Qiu, S.; Ma, C.; Hu, Y. Synthesis of a hyperbranched phosphorus-containing polyurethane as char forming agent combined with ammonium polyphosphate for reducing fire hazard of polypropylene. Polym. Degrad. Stab. 2019, 165, 207-219. [CrossRef]

12. Qiu, S.; Ma, C.; Wang, X.; Zhou, X.; Feng, X.; Yuen, R.K.; Hu, Y. Melamine-containing polyphosphazene wrapped ammonium polyphosphate: A novel multifunctional organic-inorganic hybrid flame retardant. J. Hazard. Mater. 2018, 344, 839-848. [CrossRef] [PubMed]

13. Jiang, Z.; Liu, G. Microencapsulation of ammonium polyphosphate with melamine-formaldehydetris(2-hydroxyethyl)isocyanurate resin and its flame retardancy in polypropylene. RSC Adv. 2015, 5, 88445-88455. [CrossRef]

14. Shao, Z.-B.; Deng, C.; Tan, Y.; Chen, M.-J.; Chen, L.; Wang, Y.-Z. Flame retardation of polypropylene via a novel intumescent flame retardant: Ethylenediamine-modified ammonium polyphosphate. Polym. Degrad. Stab. 2014, 106, 88-96. [CrossRef]

15. Shao, Z.-B.; Deng, C.; Tan, Y.; Yu, L.; Chen, M.; Chen, L.; Wang, Y.-Z. Ammonium polyphosphate chemically-modified with ethanolamine as an efficient intumescent flame retardant for polypropylene. J. Mater. Chem. A 2014, 2, 13955-13965. [CrossRef]

16. Tan, Y.; Shao, Z.-B.; Chen, X.-F.; Long, J.-W.; Chen, L.; Wang, Y.-Z. Novel Multifunctional Organic-Inorganic Hybrid Curing Agent with High Flame-Retardant Efficiency for Epoxy Resin. ACS Appl. Mater. Interfaces 2015, 7, 17919-17928. [CrossRef]

17. Shao, Z.-B.; Deng, C.; Tan, Y.; Chen, M.-J.; Chen, L.; Wang, Y.-Z. An Efficient Mono-Component Polymeric Intumescent Flame Retardant for Polypropylene: Preparation and Application. ACS Appl. Mater. Interfaces 2014, 6, 7363-7370. [CrossRef]

18. Shang, S.; Yuan, B.; Sun, Y.; Chen, G.; Huang, C.; Yu, B.; He, S.; Dai, H.; Chen, X. Facile preparation of layered melamine-phytate flame retardant via supramolecular self-assembly technology. J. Colloid Interface Sci. 2019, 553, 364-371. [CrossRef]

19. Shang, S.; Ma, X.; Yuan, B.; Chen, G.; Sun, Y.; Huang, C.; He, S.; Dai, H.; Chen, X. Modification of halloysite nanotubes with supramolecular self-assembly aggregates for reducing smoke release and fire hazard of polypropylene. Compos. B Eng. 2019, 177, 107371. [CrossRef]

20. Dong, H.; Yuan, B.; Qi, C.; Li, K.; Shang, S.; Sun, Y.; Chen, G.; Zhang, H.; Chen, X. Preparation of piperazine cyanurate by hydrogen-bonding self-assembly reaction and its application in intumescent flame-retardant polypropylene composites. Polym. Adv. Technol. 2019, 31, 1027-1037. [CrossRef]

21. Sunab, Y.; Yuana, B.; Shanga, S.; Zhangc, H.; Shid, Y.; Yue, B.; Qia, C.; Donga, H.; Chena, X.; Yangb, X. Surface modification of ammonium polyphosphate by supramolecular assembly for enhancing fire safety properties of polypropylene. Compos. B Eng. 2020, 181, 107588. [CrossRef]

22. Jin, X.; Sun, J.; Zhang, J.S.; Gu, X.; Bourbigot, S.; Li, H.; Tang, W.; Zhang, S. Preparation of a Novel Intumescent Flame Retardant Based on Supramolecular Interactions and Its Application in Polyamide 11. ACS Appl. Mater. Interfaces 2017, 9, 24964-24975. [CrossRef] [PubMed]

23. Jin, X.; Cui, S.-P.; Sun, S.; Gu, X.; Li, H.; Sun, J.; Zhang, S.; Bourbigot, S. The Preparation of an Intumescent Flame Retardant by Ion Exchange and Its Application in Polylactic Acid. ACS Appl. Polym. Mater. 2019, 1, 755-764. [CrossRef] 
24. Duan, L.; Yang, H.; Song, L.; Hou, Y.; Wang, W.; Gui, Z.; Hu, Y. Hyperbranched phosphorus/nitrogen-containing polymer in combination with ammonium polyphosphate as a novel flame retardant system for polypropylene. Polym. Degrad. Stab. 2016, 134, 179-185. [CrossRef]

25. Ren, Y.; Yuan, D.; Li, W.; Cai, X. Flame retardant efficiency of KH-550 modified urea-formaldehyde resin cooperating with ammonium polyphosphate on polypropylene. Polym. Degrad. Stab. 2018, 151, $160-171$. [CrossRef]

26. Guan, Y.-H.; Huang, J.-Q.; Yang, J.-C.; Shao, Z.-B.; Wang, Y.-Z. An Effective Way to Flame-Retard Biocomposite with Ethanolamine Modified Ammonium Polyphosphate and Its Flame Retardant Mechanisms. Ind. Eng. Chem. Res. 2015, 54, 3524-3531. [CrossRef]

27. Wang, D.; Wang, Y.; Li, T.; Zhang, S.; Ma, P.; Shi, D.; Chen, M.; Dong, W. A Bio-Based Flame-Retardant Starch Based on Phytic Acid. ACS Sustain. Chem. Eng. 2020, 8, 10265-10274. [CrossRef]

28. Xiong, Z.; Zhang, Y.; Du, X.; Song, P.; Fang, Z. Green and Scalable Fabrication of Core-Shell Biobased Flame Retardants for Reducing Flammability of Polylactic Acid. ACS Sustain. Chem. Eng. 2019, 7, 8954-8963. [CrossRef]

29. Tian, N.; Wen, X.; Jiang, Z.; Gong, J.; Wang, Y.; Xue, J.; Tang, T. Synergistic Effect between a Novel Char Forming Agent and Ammonium Polyphosphate on Flame Retardancy and Thermal Properties of Polypropylene. Ind. Eng. Chem. Res. 2013, 52, 10905-10915. [CrossRef]

30. Jiang, W.; Hao, J.-W.; Han, Z. Study on the thermal degradation of mixtures of ammonium polyphosphate and a novel caged bicyclic phosphate and their flame retardant effect in polypropylene. Polym. Degrad. Stab. 2012, 97, 632-637. [CrossRef]

31. Zheng, Z.; Liu, Y.; Zhang, L.; Dai, B.; Yang, X.; Wang, H. Fabrication of halogen-free ammonium phosphate with two components via a simple method and its flame retardancy in polypropylene composites. J. Therm. Anal. Calorim. 2016, 127, 2013-2023. [CrossRef]

32. Ran, J.C.; Qiu, J.D.; Xie, H.L.; Lai, X.J.; Li, H.Q.; Zeng, X.R. Combination effect of zirconium phosphate nanosheet and PU-coated carbon fiber on flame retardancy and thermal behavior of PA46/PPO alloy. Compos. B. Eng. 2019, 166, 621-632. [CrossRef]

33. Huang, W.; He, W.; Long, L.; Yan, W.; He, M.; Qin, S.; Yu, J. Highly efficient flame-retardant glass-fiber-reinforced polyamide 6T system based on a novel DOPO-based derivative: Flame retardancy, thermal decomposition, and pyrolysis behavior. Polym. Degrad. Stab. 2018, 148, 26-41. [CrossRef]

34. Qiao, Y.H.; Wang, Y.B.; Zou, M.H.; Xu, D.H.; Pan, Y.T.; Luo, Z.L.; Wang, B.B. One-Step Synthesis of Highly Efficient Oligo (phenyl phosphonic Dihydroxypropyl Silicone Oil) Flame Retardant for Polycarbonate. Polymers 2019, 11, 1977. [CrossRef] [PubMed]

Publisher's Note: MDPI stays neutral with regard to jurisdictional claims in published maps and institutional affiliations.

(C) 2020 by the authors. Licensee MDPI, Basel, Switzerland. This article is an open access article distributed under the terms and conditions of the Creative Commons Attribution (CC BY) license (http://creativecommons.org/licenses/by/4.0/). 